\title{
Processes in collaborative entrepreneurship: a longitudinal case study of how multiple actors exploit a radically new opportunity
}

\author{
Edith Andresen • Heléne Lundberg • Joakim Wincent
}

Published online: 21 February 2014

(C) Springer Science+Business Media New York 2014

\begin{abstract}
In this longitudinal case study, the authors integrate the theory on social movement with the entrepreneurship literature on opportunity discovery, evaluation, and exploitation. They construct a model on collaborative entrepreneurial processes in which multiple partners are involved in identifying, forming, and exploiting an opportunity. Three interdependent subprocesses are identified: (1) the opportunity conceptualization dialogue, (2) resource mobilization and, (3) legitimacy building, which significantly contribute to our understanding of how individuals across different organizations become engaged in collaborative entrepreneurial processes. The model of collaborative entrepreneurial processes complements traditional models of the entrepreneurial process, which place the individual entrepreneur at the center of the process and does not consider group mobilization processes in which the actors aim to be creative and innovative in collaborating with actors from other organizations or firms.
\end{abstract}

Keywords Entrepreneurship - Collaborative entrepreneurship · Resource mobilization · Legitimacy building $\cdot$ Social movement · Opportunity

\footnotetext{
E. Andresen $\cdot$ H. Lundberg

Department of Social Sciences, Mid Sweden University, Sundsvall, Sweden

E. Andresen

e-mail: edith.andresen@miun.se

H. Lundberg

e-mail: helene.lundberg@miun.se

J. Wincent $(\bowtie)$

Department of Management and Organization, Hanken School of Economics, Helsinki, Finland e-mail: joakim.wincent@hanken.fi

J. Wincent

e-mail: joakim.wincent@1tu.se

J. Wincent

Department of Business Administration, Technology and Social Sciences, Luleå University of Technology, Luleå, Sweden
} 


\section{Introduction}

The entrepreneurial process has been studied extensively from the individual's perspective, which captures the decisions in which individual entrepreneurs engage when deciding whether to proceed or exit at the various steps of the entrepreneurial process. Such steps range from discovering an opportunity to exploiting it into a product or service (Eckhardt and Shane 2003; Alvarez and Barney 2007). It is not uncommon, however, that economic development through entrepreneurship is a result of collective actions in group processes, which involve multiple partners embedded in network structures (Johannisson et al. 2002; Thornton et al. 2011). Process-oriented network perspectives on entrepreneurship have not been described to a great extent (Audretsch et al. 2011), but the need for dialogue that recognizes such opportunities has been acknowledged (Zahra 2008) together with calls for a more embedded view on entrepreneurship (Ribeiro-Soriano and Urbano 2009).

With the lack of received models of collaborative entrepreneurship, the steps and characteristics of this process are not clearly described in prior literature (Short et al. 2011; Venkataraman et al. 2012). This paper, therefore, seeks to answer the following research question: "What are the elements that form and affect collaborative entrepreneurial processes?"

As such, the paper contributes to previous research in that we integrate theory on social movement with entrepreneurship opportunity literature into a model on collaborative entrepreneurial processes where multiple partners are involved in the identification, formation, and exploitation of an opportunity. We identify an elementary model that acknowledges three interdependent sub-processes: (1) opportunity conceptualization dialogue, (2) mobilizing resources, and (3) building legitimacy, which contribute to our understanding of how individuals across different organizations get engaged in collaborative entrepreneurial processes. Overall, our model of collaborative entrepreneurial processes complements the traditional models of the entrepreneurial process, which place the individual entrepreneur at the center of the entrepreneurial process and does not consider group-mobilization processes and how entrepreneurs collaborate with each other (Bergh et al. 2011).

\section{Research methods}

We induced our model from a longitudinal case study of a unique collaborative entrepreneurship initiative called the Biorefinery of the Future initiative in light of above-mentioned shortcoming in previous literature as case studies are known to be particularly well suited to new research areas (Eisenhardt 1989; Rowley 2002). It is an in depth, single case study depicted as a narrative closely intertwined with the theory, supported by quotations from key informants (Eisenhardt and Graebner 2007) and thus a qualitative approach to develop a process model of collaborative entrepreneurship, which does not restrict that it could be extended and drawn upon in traditional quantitative hypotheses tests in further research of collective entrepreneurship (Voss et al. 2002). The case examined a Swedish grouping of individuals from companies, municipalities, and universities that were aiming to create, promote, and co-invent products and processes based on lignocellulosic feedstock. The companies involved in 
the Biorefinery of the Future initiative are located in the same geographical area. The model highlights a social movement theory explanation of how single individuals engaged and mobilized others into collaborative entrepreneurial processes. The Biorefinery of the Future included 29 participants active in the process, all of whom were willing to participate in the present study.

Data collection

Two of the authors formed a team that collected data over a 5-year period, 2005-2010, using multiple methods (Barratt et al. (2011) such as observations, interviews, and written sources such as reports, informational and marketing materials, project applications, and project decisions. This allowed us to collect a rich body of information to capture both the complexity of and the patterns in the collaborative entrepreneurial process in line with Stuart et al. (2002). We attended meetings, including presentations and evaluations and reviewed internal information. We took extensive notes on what was said and done and how individuals interacted. We paid particular attention to group mobilization and entrepreneurship. The observations generated a more holistic understanding of the ongoing collaborative entrepreneurial process. Table 1 summarizes the positions of the 28 respondents from the Biorefinery of the Future initiative that we interviewed. In addition, the analysis is based on observations from 10 meetings with network members, including employees and the present and former CEO's (Chief Executive Officer) actions at local and regional meetings and as they participated in network activities.

Data analysis

The interviews were transcribed and summarized in a report presented to the respondents. We also compiled all the archival data and observations to triangulate and

Table 1 Number and distribution of respondents

\begin{tabular}{ll}
\hline Number of respondents & Affiliation \\
\hline 11 & Member firm representatives (managers) \\
3 & University representatives (professors) \\
3 & Local authority representatives \\
2 & Municipally owned firm representatives (managers) \\
3 & County administrative board representatives \\
2 & The present (from January 2011) and the former CEO of Processum \\
2 & Administrator employed by Processum \\
2 & Development engineers employed by Processum \\
\hline
\end{tabular}

The semi-structured interviews were based on an interview guide that included 25 open-ended questions. The questions concerned historical background and important events, actions, resource provision, reputation issues, experiences, and changes to the initiative. They also concerned the cooperative process and its driving forces and obstacles, particularly communication issues and the role of the CEO and other coordinators played 
advance our understanding of the entrepreneurial process of the Biorefinery of the Future initiative.

The model and analysis presented in the present paper resulted from an iterative process starting in induction in which we pended among our data, theory, and the emergent model and study results in line with Eisenhardt and Graebner (2007) and Voss et al. (2002). In the data analysis, we looked for commonalities, key themes, and patterns, but also for contrasts and irregularities. Both similarities and differences could be used to identify model constructs and key mechanisms linking model constructs (Coffey and Atkinson 1996). Ultimately, we noticed that the social movement literature and a set of contributions in the entrepreneurship literature on opportunity recognition supported theory integration and the model presented. We discussed the findings within the group of researchers allowing different perspectives of multiple researchers as recommended by Eisenhardt (1989) and Barratt et al. (2011) but also with participants in the Biorefinery of the Future initiative to further clarify the entrepreneurial processes in play and to validate the processes observed.

\section{Research case and findings}

The identified model of collaborative entrepreneurship

The empirical implications of the collective entrepreneurial process described in our case and its theoretical implications for the model are presented in Fig. 1, the prominent elements of the model are elaborated upon in Table 2 and the theory driven elements of events that is behind the model construction are presented in Table 3. Our model is inspired by the social movement literature. It identifies three interdependent subprocesses: opportunity conceptualizing dialogue, resource mobilization, and legitimacy building. The case demonstrates that the opportunity conzeptualization dialogue among the actors that cooperated to explore biorefinery-related opportunities; mobilizing resources for R\&D; and building legitimacy related to mobilizing resources and supporting the initiative became key management tasks. We next discuss these essential mechanisms in the collaborative entrepreneurial process. These processes follows generic social movement processes such as that one outlined by Hambrick and Chen (2008), which means they have the potential to explain essential elements of collective entrepreneurship. As illustrated, the model starts with an entrepreneurial initiative based on an interest to explore an entrepreneurial opportunity. The first step of further conceptualizing this opportunity into an interaction is to initiate an opportunity conceptualizing dialogue in a group setting with other actors and potential partners (Arrow 1, Fig. 1). The next three interactive processes are depicted by Arrows 2, 3 and 4 of Fig. 1. A decision to exit the process may be made, of course, at any step; our model therefore illustrates a tentative process from the beginning to finalization in the form of an entrepreneurial venture (Arrow 5). We next present the narrative of the Biorefinery of the Future that has been used to create our model of collaborative entrepreneurship and the model presented in Fig. 1. 


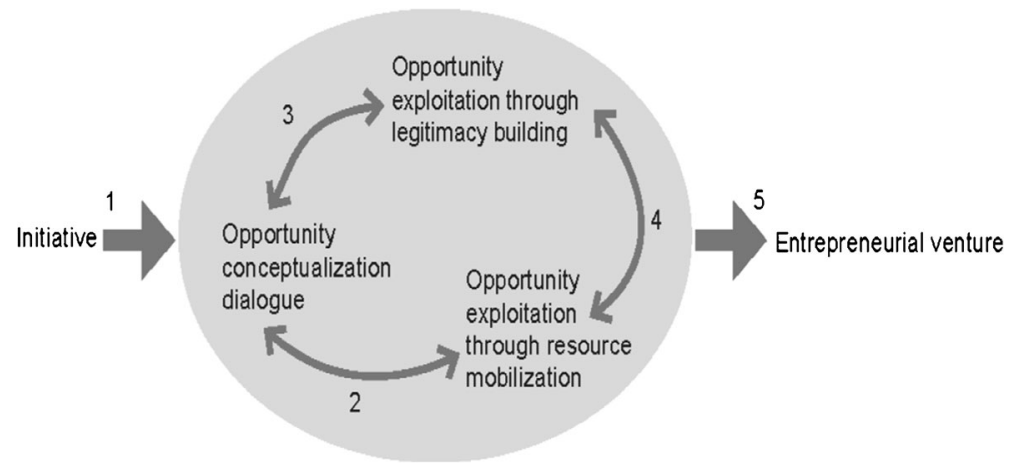

Fig. 1 A model of collaborative entrepreneurial processes

\section{Initiating the Biorefinery of the Future}

Our case description starts when a large multinational company (MoDo) which operated within the forestry sector focusing pulp and paper industry reorganized its business operations in the region of Västernorrland in northern Sweden by focusing on its core business and selling off parts of the business. MoDo is a large and important actor in

Table 2 Elements of the collaborative entrepreneurial process model

Model elements Stage characteristics

Initiative

Opportunity conceptualization dialogue

Opportunity exploitation through resource mobilization

Opportunity exploitation through legitimacy building

Entrepreneurial venturing
- Preconditions that support the birth of a collective entrepreneurship initiative: Existence of entrepreneurial attitudes and experience, alertness, prior information, cognitive frames and self-confidence.

- Network activities that facilitate information access and exchange.

- Social, trusting, and cooperative relationships that promote resource sharing.

- Action, interaction, evaluation, and discovery of further opportunities and ways to conceptualize them.

- Thereafter, renewed action followed by internal and external network reactions from influential parties.

- Willingness and ability to act, which leads to discovering how to act, which furthers action. Decisions concerning resource mobilization, in reaction to feedback from the opportunity discovery/creation process, which facilitate further access to financial backing and create ties to resource providers.

- Mobilization of actors in political structures.

- Shared interests and quality of social infrastructure spurring further mobilization.

- Initiators communicating their goals as legitimate to others in the collective, as well as to people outside the collective, such as potential partners and financial backers.

- Initiators in high positions may fuel the opportunity conceptualization dialogue through personal legitimacy by virtue of their positions and through being open to adapting, the ability to spearhead efforts (e.g., lobbying for and advocating), and demonstrating a valuable contribution to society.

- A formalized venture ready to be launched in the market. 
Table 3 The entrepreneurial collaborative process of the Biorefinery of the Future initiative

\begin{tabular}{ll}
\hline Model element $\quad$ Empirical observations & $\begin{array}{l}\text { Stage characteristics and theoretical } \\
\text { model implications }\end{array}$
\end{tabular}

Initiative

\section{Opportunity conceptualization dialogue}

Opportunity exploitation through resource mobilization

\section{Willingness to act, knowledge of business, socially related initiators in leading positions. A shared threat united the group and provided an impulse. An industrial district, a networking tradition, the willingness to provide support to others and to share resources and information. Trusting relationships among the initiators.}

Initiators are alert to changes, with shared cognitive frames, selfconfidence, and relevant prior information facilitated discovering and creating opportunities. Their actions led to feedback that spurred further opportunity discovery/ creation. An increasing number of actors took part in the opportunity conceptualization dialogue.

The initiators and their cause were perceived as legitimate, which facilitated resource mobilization. With every new financier, the initiative gained more legitimacy, making it easier to persuade others to follow. Resource providers were invited to take part in the opportunity conceptualization dialogue and were approached whenever possible with a focus on relationship building.
Listed model implications with generalization possibilities:

- Preconditions that support the birth of a collective entrepreneurship initiative include the existence of entrepreneurial attitudes and experience, alertness, prior information, cognitive frames, and self-confidence.

- Network activities that facilitate information access and exchange.

- Social, trusting, and cooperative relationships promote resource sharing.

Social relationships among the initiators created trust that facilitated the opportunity conceptualizing dialogue.

Listed model implications with generalization possibilities:

- Action, interaction, evaluation, and discovery of further opportunities and ways to conceptualize them.

- Thereafter, renewed action followed by internal and external network reactions from influential parties.

Trust generated through social networks allows open dialogue, as well as informal and flexible ways of working. Social networks can be used strategically to build legitimacy and mobilize resources.

Listed model implications with generalization possibilities:

- Willingness and ability to act lead to discovering how to act, which advanced the action. Decisions concerning resource mobilization, reacting to feedback from the process of discovering and creating the opportunity, facilitate further access to financial backing and create ties to resource providers.

- Mobilizing actors in political structures.

- Shared interests and quality of social infrastructure spurred further mobilization

It is important to focus on strategic relationship-building, for example, by being active in the financiers' strategic projects and by involving 
Table 3 (continued)

\begin{tabular}{ll}
\hline Model element $\quad$ Empirical observations & $\begin{array}{l}\text { Stage characteristics and theoretical } \\
\text { model implications }\end{array}$
\end{tabular}

Opportunity exploitation through legitimacy building

Entrepreneurial venturing The biorefinery vision was made possible by winning the Vinnväxt competition. Several joint research projects are now underway, patents have been secured, and new products are being offered to the market. them in the opportunity conceptualization dialogue.

Listed model implications with generalization possibilities: initiators, and legitimacy derived from locating in an industrial district known for its competence in woodrelated production constituted a favourable starting point. The legitimacy steadily increased as one actor after another joined the initiative as partner or financier.

- Initiators communicating their goals as legitimate to others in the collective and to people outside the collective, such as potential partners and financial backers.

- Initiators in high positions may fuel the opportunity conceptualization dialogue through the personal legitimacy of their positions and being open to adapting, the ability to spearhead the effort (e.g., lobby for and advocate), and demonstrating a valuable contribution to society

Relationship building ability is vital for building legitimacy. This ability includes being able to find the right timing and to act on opportunities that many perceive as "right," or unique.

Listed model implications with generalization possibilities:

- A formalized venture is ready to be launched in the market

the region and the changes were not positively interpreted in the region. These changes prompted concern in the region; indeed, residents felt threatened as they feared fewer job opportunities and fewer resources for the research and development (R\&D) sector. Some of the former staff, now senior managers of public and private organizations, thus united the group by forming a stakeholder association in 2001 to discuss opportunities for coordination and create synergies between their now separate businesses. The collaborators discovered opportunities and support each other in matters related to R\&D cooperation and ways to handle the exploitation of these opportunities. Subsequently, a limited liability company was formed in 2002, which was owned by the 14 companies represented by those who initiated the stakeholder association. A CEO was recruited, and a board of directors was appointed. The Biorefinery of the Future concept was formulated to serve as a common platform. Increased international competition in the forestry sector inspired the companies to consider using wood-based, biorefinery-related products as substitutes for petroleum-based products. As such, and what is summarized in the coding and the theory driven insights presented in Tables 2 and 3, the entrepreneurial initiative was launched as these individuals were inspired and saw opportunities in forming new means-ends 
frameworks (Eckhardt and Shane 2003), and the presence of networking activities, established relationships and trust facilitated the initiation.

The opportunity conceptualizing dialogue

As evident in Tables 2 and 3 where the opportunity conceptualization dialogue is elaborated upon, we observed several interesting phenomena regarding the collective efforts for dialogue regarding opportunity conceptualization. Cooperation as a means to resolve a difficult situation was the first opportunity the early proponents of the Biorefinery of the Future initiative discovered. This implies that a situation in which new services, goods, or organizing methods could be introduced through forming new means or means-ends relationships (Eckhardt and Shane 2003). In line with Baker and Nelson (2005), the early proponents themselves were the source of the opportunities in terms of their interactions and to test the veracity of their perceptions regarding how to cooperate on biorefinary issues. This opportunity emerged from their interest in identifying common areas for continued growth and cooperation and from their concern about the potential adverse effects from MoDo's reorganization if timely action was not taken. Indeed, these were issues perceived as inadequately addressed by the municipality at the time. We also recognized prior entrepreneurial alertness (Kirzner 1997) arising from the initiators' former experience, deep knowledge of the field, access to vital information, and shared interest in further regional development. The initiators were self-confident, able to evaluate opportunities, occupied leading positions, and were familiar with problem-solving and decision-making. The conditions necessary for opportunity discovery, according to Shane and Venkataraman (2000), thus prevailed. As former colleagues, the initiators shared a history and thus cognitive frames, as well as beliefs and attitudes related to development issues; these were conditions Hambrick and Chen (2008) noted were vital to social movement processes. Prior long-term interactions had established social relationships and trust between the initiators; in other words, a social infrastructure constituting a basis for open dialogue and allowing informal and flexible modes of interaction was at hand. A former Board member noted:

We have experience of development activities - and they never run entirely smoothly - so we are used to something occasionally going off the rails. We have dealt with setbacks and found solutions. When we sought solutions, we dared to think in new forms. This is something I think can be difficult when you bring unknown people together.

The initiators chose to act without complete information regarding what the cooperation opportunity would entail, which is in agreement with Alvarez and Barney's (2007) theory of opportunity creation. The focus was initially on practical functions, such as sharing premises, receptions, and library services. During the course of talks (i.e., the conceptualization dialogue), however, and as the initiators acted and interacted in a common environment to test the veracity of their perceptions (Alvarez and Barney 2007; Zahra 2008; Short et al. 2011) new opportunities were discovered and the level of ambition rose. One of the Board members noted: 
We did not realize at the outset what the companies had in common. It was quite clear that the common denominator was process technology and technology based on wood, but it took about a year to clarify the strategy.

The first opportunities for R\&D cooperation were thus discovered, communicated, evaluated, and grasped, which illustrates how opportunity discovery and creation are integrated in the opportunity conceptualization dialogue concept portion of Fig. 1. Resembling Hambrick and Chen's (2008) theoretical work on social movements, some ideas related to existing fields fell outside the scope of the firms due to the focus on alternative and complementary techniques. The initiators acted and interacted to exploit the opportunities and were able to discover new opportunities and convince private and public financiers to invest in R\&D. In other words, their interactions in conceptualizing the opportunity facilitated mobilizing resources and an increasing number of actors, which in turn boosted legitimacy and facilitated further resource mobilization. The dialogue also advanced the prospects of cooperation as it promoted reciprocity strategies, which Dhanaraj and Parkhe (2006) argued were of importance.

\section{Opportunity exploitation through resource mobilization}

We also observed a process which we label exploiting opportunities by mobilizing resources. As indicated in Tables 2 and 3, the initiators needed resources to exploit the identified R\&D cooperation opportunities. As one Board member said:

Ideas emerged as to how we might create a basis for such high-risk research using public funding. There was no scope [for doing so] in individual companies, and it is not easy for individual companies to obtain public funding directly, so we saw a need to create a platform.

As further evident in the Tables 2 and 3, representatives of the county administration were included in the opportunity conceptualizing dialogue and were supplied with information about available public funding and how to apply for it and were willing and able to act on that information. Over time, funding applications were directed successfully to stakeholders, private foundations, the municipality, the county, and the European Union's Objective 1 programme. The strategy used to obtain funding was to prioritize relationship building by participating in meetings with resource providers. This strategy was chosen because creating opportunities, a vital element of the opportunity conceptualizing dialogue, is a relational process that includes actors constantly relating to their environment, to what is going on, what has worked previously, and what will recur (Fletcher 2006). Consequently, the CEO was involved in several dialogues with private and public actors concerning strategic development issues. He was thereby able to influence their decision making and discuss and anchor the needs and visions of the Biorefinery of the Future initiative in a way that led to resource mobilization related decisions in member companies as well as in institutions financing regional R\&D. A County administrator shared this observation:

The CEO understood that it was important to have relationships with the financiers. The initiators' commitment to the County's efforts can be viewed in two 
ways - they took part without getting paid and participated at all levels - but this also meant that they had opportunities to influence our actions. This interaction enriched the county.

At an early stage, a private foundation awarded grants. The initiative then gained increased legitimacy, which facilitated access to other public/political (for example the municipality and the county of Västernorrland), and private investors and their resources. This expansion coincided with the description of a social movement processes stressing the importance of the interactions among opportunity conceptualizing dialogue, mobilizing resources and building legitimacy. The municipality was clear in its support. The CEO explained:

The municipality's work on visions matched ours, and during their work on Biorefinery-related questions, they always invited us to meet high officials from the government and so on. This way we got acknowledged, gained increased legitimacy, and became known in such circles, which facilitated resource mobilization.

The CEO's statement and observation are compatible with the theories of Hambrick and Chen (2008) and Swaminathan and Wade (2000) regarding the significance of legitimacy for mobilizing resources. However, the financiers not only provided funding, they also shared their interest, knowledge, social infrastructure and experience and suggested some requirements for how to run the operation. A Board member noted:

All the financiers felt part of our development process and often participated in meetings. The ideas have grown through a dialogue to which all parties have contributed.

Another Board member was also on the board of a domestic R\&D funding organization Vinnova and consequently had first-hand information on the Vinnväxt competition. This member knew what was required, what support and resources were available, whom to contact, and what areas of development were regarded as "hot." In other words, the Board member had special information that met the conditions for opportunity discovery specified by Shane and Venkataraman (2000). The Board followed her advice and decided to enter the national Vinnväxt ${ }^{1}$ competition. By involving additional actors from universities and from the public and private sectors in the opportunity conceptualizing dialogue further resources were mobilized and the concept gained increased legitimacy with every new financier as indicated in Fig. 1.

\footnotetext{
${ }^{1}$ The Vinnväxt programme takes the form of a competition for businesses in various Swedish regions. Its aim is to promote sustainable growth by developing internationally competitive research and innovation environments in specific growth fields. The winning regions receive funding of up to SEK 10 million per year for 8 years. The objective is that the winners will become internationally competitive in their fields within this period. A prerequisite for the programme is the players from the private, public, and research sectors, as well as from the political sphere participate actively.
} 
Opportunity exploitation through legitimacy building

Our data and model clearly indicate that exploiting opportunities by building legitimacy was a critical process. As outlined in Tables 2 and 3, the cause of establishing a biorefinery was a shared legitimate cause regarded as legitimate, because environmental issues are considered to be of utmost importance in Sweden. Furthermore, the initiators, through their leading positions in the companies they now represented, had the personal legitimacy required to advance the process and persuade others to follow as Zimmerman and Zeitz (2002) and Hambrick and Chen (2008) underlined. They also had the ability to communicate goals related to the value of participation to people within and outside the collective as well as the knowledge about how to conform to rules and regulations (Zimmerman and Zeitz 2002) in a way that further built their legitimacy. There was an understanding that the initiators were acting in the interest of both themselves and others, because they belonged to an industrial district much like those described by Becattini (1991) and shared its solidarity-based and supportive industrial culture.

In 2006, Umeå University reorganized its chemistry department. The chairman of a private foundation financing the Biorefinery of the Future initiative had a social relationship with the university's new vice chancellor and could help establish contacts between the university and the Biorefinery initiative. His support and advocacy increased the legitimacy of the initiative, which increased even more when the vice chancellor later joined the Biorefinery board. In other words and what is also outlined in Tables 2 and 3, the chairman used his social networks to build the foundations for a new venture - a common strategy according to Jack and colleagues (2008). When the university decided to commit itself to the initiative, the decision was based on several factors, including local industrial tradition, the companies' abilities, the initiative's potential, private foundation support, positive response from the municipality and the county administrative board, and Board and CEO competence. The university's decision was crucial to the initiative's development, because it both created access to vital research expertise and further increased the legitimacy of the initiative, which in turn attracted more resourceful actors. This progress resembles the process of social movement described by Hambrick and Chen (2008). The fact that a Board representative also sat on the board of the R\&D funding organization Vinnova arranging the Vinnväxt competition was another factor that increased legitimacy.

We have already touched on the interactive relationship between legitimacy and resource mobilization. In sum, early stage funding from the prestigious private foundation increased the legitimacy of the Biorefinery of the Future initiative in the eyes of other financiers. As shown in Fig. 1, in turn, rendered further backing and resource mobilization as Hambrick and Chen (2008) and Wincent et al. (2010) argued. Furthermore, by applying a strategy of participating actively in a wide range of meetings and focusing on building relationships, more and more actors became involved, which further increased the initiative's legitimacy. Relational proximity to resource providers created the closeness required for an understanding of what needs had to be met to secure their support. This proximity increased over time under the direction of the CEO. The demands, opinions, and knowledge advanced by, for example, the active fund providers in personal interaction with their contacts, contributed to the conceptualization dialogue that helped develop the Biorefinery concept. This is in line with Thornton and colleagues (2011) who argued 
that personal interaction is the main resource of innovative behavior and thus opportunity recognition. Figure 1 illustrates these interactive processes.

Collaborative entrepreneurial venturing

Tables 2 and 3 further show that the outcome of the process - the collaborative venture - is something that was an outcome of the collaborative entrepreneurial efforts. The opportunity conceptualizing dialogue ultimately led to discovering a new funding opportunity: participating in a national public R\&D competition for long-term financing (8 years) called Vinnväxt. Increased collaboration with the local university added resources and legitimacy to the initiative and inspired other universities and companies to join as well. In 2008, the number of associated organizations had increased markedly, and the Biorefinery of the Future initiative won the R\&D competition.

As illustrated in Fig. 1, the initiators were able to form a collaborative entrepreneurial venturing system to continue opportunity conceptualization dialogues, legitimacy building, and resource mobilization. Several joint research projects are under way, patents have been secured, and new products are being offered on the market. Examples of such outcomes are product development on lignosulphonate and an inline chemical analysis tool based on NIR-technology.

\section{Conclusion and implications}

Previous research has devoted significant effort to examining traditional entrepreneurial processes and opportunity exploitation models that assist our understanding of why individual entrepreneurs engage in recognizing and acting on opportunities. With a few exceptions, only minor attempts have explored how collaborative opportunity recognition occurs when several individuals are involved and engaged in collaborative entrepreneurial processes, cooperating across company, government, and university boundaries.

Using a rich case description from a collective of actors that exploited a radical opportunity, we developed a model of collaborative entrepreneurial processes (Fig. 1) and have explained and elaborated on its theoretical and empirical connections. The model includes three interdependent subprocesses that illustrate how a group of actors satisfies an identified, unsatisfied need. These subprocesses have clear links to the social movement literature, which discusses why individuals decide to participate in collective action (Gould 1993). Those interested in conceptualizing dialogues, resource mobilization, and legitimacy building (Arbuthnott et al. 2010; Hambrick and Chen 2008) will also find value in our model when we combine this model with the entrepreneurship literature of opportunity recognition (Shane and Venkataraman 2000; Alvarez and Barney 2007; Short et al. 2011) and claim integration with collaborative entrepreneurial processes. In doing so, we develop a model that contributes to research and theory at the intersection of social movement and entrepreneurship. Although social movement theory has been recognized in the general management literature (Hambrick and Chen 2008), it has not yet been integrated with the entrepreneurship discourse. We argue that collaborative entrepreneurial processes feature interdependence among three subprocesses often mentioned in the social movement 
literature; namely, opportunity conceptualization dialogue, opportunity exploitation through resource mobilization, and opportunity exploitation through legitimacy building. Here, entrepreneurial formation occurs in interactive sequences and is relationally and communally constituted (Fletcher 2006; Short et al. 2011).

Our contribution lends further clarification to collaborative entrepreneurial processes and its influencing contingencies. This is much needed due to the lack of research and formal models in this field (Berg et al. 2011). This approach favors discussing the venture's evolution though joint activity (Venkataraman et al. 2012; Dale Meyer 2011; Wincent and Örtqvist 2009). Our contribution includes insight into the role of networks in facilitating access to resources and discovering and creating opportunities, and the role of resources and opportunities in creating a network (Hoang and Antoncic 2003).

Although the strength of abduction-oriented iterative case research, like that described in the present paper, is used to generate new ideas and empirical insights for theorizing, we acknowledge limitations in validating existing ideas. However, we believe that the model opens up avenues for further research and has implications for the entrepreneurship literature related to collaborative entrepreneurial processes, opportunities, and the process of exploitation. We realize that the model is generic and that hypothesis testing based upon the processes outlined in Fig. 1 could potentially create more insights than we manage to do in this initial study. Our model suggests building relationships and having a dialogue with a multitude of actors enables anchoring, creating a sense of shared responsibility, and establishing a common understanding of the opportunity, all of which facilitate resource mobilization and legitimacy building. We thus believe that the model should encourage further research to suggest and formally test situations whether interaction in the form of relationship building and dialogue can contribute to soften prestige in developing opportunities together, disarm conflict, and create the possibility of win-win solutions that mobilize the group of entrepreneurs involved in developing the opportunity, as well as ultimate influences of profitable business cooperation and efficiency. For example, in terms of efficiency our model could be used to posit early in the process, it is crucial to identify and approach legitimate resource providers that are willing to participate in developing as well as spearheading the cause/case/idea. Again, we believe our model needs additional testing and that it should mostly be understood as a tool for further theory development on collective entrepreneurship.

\section{References}

Alvarez, S. A., \& Barney, J. B. (2007). Discovery and creation: alternative theories or entrepreneurial action. Strategic Entrepreneurship Journal, 1, 11-26.

Arbuthnott, A., Eriksson, J., \& Wincent, J. (2010). When a new industry meets traditional and declining ones: an integrative approach towards dialectics and social movement theory in a model of regional industry emergence processes. Scandinavian Journal of Management, 26(3), 290-308.

Audretsch, D. B., Aldridge, T. T., \& Sanders, M. (2011). Social capital building and new business formation: a case study in Silicon Valley. International Small Business Journal, 29(2), 152-169.

Baker, T., \& Nelson, R. E. (2005). Creating something from nothing: resource construction through entrepreneurial bricolage. Administrative Science Quarterly, 50, 329-366.

Barratt, M., Choi, T. Y., \& Li, M. (2011). Qualitative case studies in operations management: trends, research outcomes, and future research implications. Journal of Operations Management, 29, 329-342.

Becattini, G. (1991). Italian industrial districts: problems and perspectives. International Journal of Management and Organization, 21(1), 83-90. 
Bergh, P., Thorgren, S., \& Wincent, J. (2011). Entrepreneurs learning together: the importance of building trust for learning and exploiting business opportunities. International Entrepreneurship and Management Journal, 7(1), 17-37.

Coffey, A., \& Atkinson, P. (1996). Making sense of qualitative data: Complementary research strategies. Thousand Oaks: Sage.

Dale Meyer, G. (2011). The reinvention of academic entrepreneurship. Journal of Small Business Management, 49(1), 1-8.

Dhanaraj, C., \& Parkhe, A. (2006). Orchestrating innovation networks. Academy of Management Review, 31(3), 659-669.

Eckhardt, J. T., \& Shane, S. A. (2003). Opportunities and entrepreneurship. Journal of Management, 29(3), 333-349.

Eisenhardt, K. M. (1989). Building theories from case study research. Academy of Management Review, 14(4), $532-550$.

Eisenhardt, K. M., \& Graebner, M. E. (2007). Theory building from cases: opportunities and challenges. Academy of Management Review, 50(1), 25-32.

Fletcher, D. (2006). Entrepreneurial processes and the social construction of opportunity. Entrepreneurship \& Regional Development, 18, 421-440.

Gould, R. V. (1993). Collective action and network structure. American Sociological Review, 58, $182-196$.

Hambrick, D. C., \& Chen, M. J. (2008). New academic fields as admittance seeking social movements: the case of strategic management. Academy of Management Review, 33(1), 32-54.

Hoang, H., \& Antoncic, B. (2003). Network-based research in entrepreneurship. A critical review. Journal of Business Venturing, 18, 165-187.

Jack, S., Dodd, S. D., \& Anderson, A. R. (2008). Change and the development of entrepreneurial networks over time: a processual perspective. Entrepreneurship \& Regional Development, 20, 125-159.

Johannisson, B., Ramirez-Pasillas, M., \& Karlsson, G. (2002). The institutional embeddedness of local interfirm networks: a leverage for business creation. Entrepreneurship and Regional Development: An International Journal, 14(4), 297-315.

Kirzner, I. M. (1997). Entrepreneurial discovery and the competitive market process: an Austrian approach. Journal of Economic Literature, $V, 60-85$.

Ribeiro-Soriano, D., \& Urbano, D. (2009). Overview of collaborative entrepreneurship: an integrated approach between business decisions and negotiations. Group Decision and Negotiation, 18, 419-430.

Rowley, J. (2002). Using case studies in research. Management Research News, 25(1), 16-26.

Shane, S., \& Venkataraman, S. (2000). The promise of entrepreneurship as a field of research. Academy of Management Review, 25(1), 217-226.

Short, J. C., Ketchen, D. J., Jr., Shook, C. L., \& Ireland, R. D. (2011). The concept of “opportunity” in entrepreneurship research: past accomplishments and future challenges. Journal of Management, 35(1), 40-65.

Stuart, I., McCutcheon, D., Handfield, R., McLachlin, R., \& Samson, D. (2002). Effective case research in operations management: a process perspective. Journal of Operations Management, 20, 419-433.

Swaminathan, A., \& Wade, J. B. (2000). Social movement theory and the evolution of new organizational forms. In C. B. Schoonhoven \& E. Romanelli (Eds.), The entrepreneurship dynamic in industry evolution. Palo Alto: Stanford University Press.

Thornton, P. H., Ribeiro-Soriano, D., \& Urbano, D. (2011). Socio-cultural factors and entrepreneurial activity: an overview. International Small Business Journal, 29(2), 105-118.

Venkataraman, S., Sarasvathy, S. D., Dew, N., \& Forster, W. R. (2012). Reflections on the 2010 AMR Decade Award: whither the promise? Moving forward with entrepreneurship as a science of the artificial. Academy of Management Review, 37(1), 21-33.

Voss, C., Tsikriktsis, N., \& Frohlich, M. (2002). Case research in operations management. International Journal of Operations \& Production Management, 22(2), 195-219.

Wincent, J., \& Örtqvist, D. (2009). A comprehensive model of entrepreneur role stress antecedents and consequences. Journal of Business and Psychology, 24(2), 225-243.

Wincent, J., Örtqvist, D., Eriksson, J., \& Autio, E. (2010). The more the merrier? The effect of group size on effectiveness in SME funding campaigns. Strategic Organization, 8, 43-68.

Zahra, S. A. (2008). The virtuous cycle of discovery and creation of entrepreneurial opportunities. Strategic Entrepreneurship Journal, 2, 243-257.

Zimmerman, M. A., \& Zeitz, G. J. (2002). Beyond survival: achieving new venture growth by building legitimacy. Academy of Management Review, 27(3), 414-431. 